

\title{
Intrinsic defects and their influence on the chemical and optical properties of TiO2x films
}

N Laidani, P Cheyssac, J Perrière, R Bartali, G Gottardi, I Luciu, V Micheli

\section{To cite this version:}

N Laidani, P Cheyssac, J Perrière, R Bartali, G Gottardi, et al.. Intrinsic defects and their influence on the chemical and optical properties of TiO2x films. Journal of Physics D: Applied Physics, 2010, 43 (48), pp.485402. 10.1088/0022-3727/43/48/485402 . hal-00574379

\section{HAL Id: hal-00574379 \\ https://hal.science/hal-00574379}

Submitted on 8 Mar 2011

HAL is a multi-disciplinary open access archive for the deposit and dissemination of scientific research documents, whether they are published or not. The documents may come from teaching and research institutions in France or abroad, or from public or private research centers.
L'archive ouverte pluridisciplinaire HAL, est destinée au dépôt et à la diffusion de documents scientifiques de niveau recherche, publiés ou non, émanant des établissements d'enseignement et de recherche français ou étrangers, des laboratoires publics ou privés. 


\title{
Intrinsic defects and their influence on the chemical and optical properties of $\mathrm{TiO}_{2-\mathrm{x}}$ films
}

\author{
N. Laidani ${ }^{1 *}$, P. Cheyssac ${ }^{2}$, J. Perrière ${ }^{3}$, R. Bartali ${ }^{1}$, G. Gottardi ${ }^{1}$, I. Luciu ${ }^{1,4}$ and V. Micheli ${ }^{1}$ \\ ${ }^{1}$ Fondazione Bruno Kessler, Via Sommarive, 18, 38123 Povo (Trento), Italy \\ ${ }^{2}$ Laboratoire de Physique de la Matière Condensée (UMR CNRS 6622), Université de Nice Sophia-Antipolis, \\ Parc Valrose, 06108 Nice cedex 2, France \\ ${ }^{3}$ INSP, UMR 7188 CNRS Université Paris VI, 140 rue de Lourmel, 75015 Paris, France \\ ${ }^{4}$ Dipartimento di Fisica, Università di Trento, Via Sommarive, 15, 38123 Trento (Povo), Italy \\ * Corresponding author
}

\begin{abstract}
In this work, $\mathrm{TiO}_{2}$ films produced by rf sputtering of a $\mathrm{TiO}_{2}$ target, in argon and argon-oxygen plasmas were studied. The oxygen content in the feed gas was varied in a range of $3 \%-20 \%$. The chemical composition and structure of films were characterized by Rutherford backscattering spectrometry (RBS), X-ray photoelectron spectroscopy (XPS) and X-ray diffraction. Important information about the intrinsic defects of the films and their effects on the optical properties as well as a scheme of the energy band structure of the films could be derived from a combined use of optical spectroscopy and XPS.
\end{abstract}

Keywords: $\mathrm{TiO}_{2}$ films, optical properties, electronic properties, defects, sputtering PACS: 68.55.ag; 68.55.Ln; 78.20.-e; 78.20.Ci; 78.40.-q; 81.05.Gc; 81.15.Cd

\section{I- Introduction}

Titanium oxide is an important material widely applied to many fields such as water electrolysis and photocatalysis $[1,2]$, photovoltaics where it is employed as the active part of the cells for solar energy conversion [3] and transparent conductive oxides for the production of transparent electrodes equivalent to those of indium tin oxide (ITO) [4-6]. The latter enters the structure of new generation solar cells, organic light emitting devices (OLEDs) and flat panel displays ; replacing ITO by a cheaper and more abundant $\mathrm{TiO}_{2}$ will lower the cost of devices. When doped with rare earth, $\mathrm{TiO}_{2}$ can be used to increase the silicon-based solar cell efficiency by modifying the solar radiation, through the conversion of high energy photons to other photons with a lower energy, more useful for silicon absorption $[7,8]$.

A common feature unifies all these application fields, which is linked to the defects in $\mathrm{TiO}_{2}$ structure which strongly determine its electronic, electrical, optical properties and photoactivity. A great amount of work, mainly theoretical, has been done to investigate the nature, the energetics, the chemistry, the creation, the relaxation and the role of the defects states in 
titania's band gap [9-14]. These studies treated the crystalline phases, bulk rutile or anatase, of $\mathrm{TiO}_{2}$, but very few works have been reported on defect peculiarities in titanium oxide films. In this work, a joint study was conducted to determine the relevant optical, electronic and defect properties of thin $\mathrm{TiO}_{2-\mathrm{x}}$ films produced by $\mathrm{RF}$ sputtering of a $\mathrm{TiO}_{2}$ target. Density and stoichiometry of films deposited in various $\mathrm{Ar}-\mathrm{O}_{2}$ mixtures and plasma conditions were derived from x-ray photoelectron spectroscopy (XPS), Rutherford backscattering spectrometry (RBS). The different phases of $\mathrm{TiO}_{2}$ were determined using X-ray diffraction (XRD). The films reflectance spectra have been measured in the visible range. The optical indices and energy gap of the material have been extracted; their interpretation allowed to define an energy band scheme and the gap states.

\section{II- Experimental details}

\section{1 The sample preparation}

A series of films has been prepared by RF sputtering under a self-bias voltage at cathode and at a $2 \mathrm{~Pa}$ pressure. $\mathrm{A} \mathrm{TiO}_{2}$ disk with $10 \mathrm{~cm}$ diameter from Goodfellow was used as target. The samples were at floating potential and were not externally heated. The sputtering gas was oxygen-containing argon. Various conditions of process were applied and are summarized in Table 1: oxygen content in argon varied from 0 to 20 vol. $\%$ and self-bias voltages at the target were $-550 \mathrm{~V}$ and $-750 \mathrm{~V}$; films are consequently labeled.

Films were deposited onto n-doped silicon (100) and 1mm thick glass substrates; their mechanical thicknesses have been determined with a stylus profilometer and serve as starting data in the optical constants calculations. The measured film thicknesses are given in Table 1.

\section{I1.2 The sample characterization}

a- $R B S$

The film composition has been determined by RBS, using a $2 \mathrm{MeV}$ Van de Graaff accelerator. The oxygen content was determined with a 5\% accuracy, due to the low RBS yield for light elements like oxygen.

\section{b- XPS}

Films were analyzed with a Scienta instrument, with AlK $\alpha$ radiation $(1486,6 \mathrm{eV})$. Both core levels and valence band spectra were acquired. All binding energies are given with respect to Fermi level $\left(\mathrm{E}_{\mathrm{F}}\right)$. 
The chemical composition and oxide stoichiometry of the films surface were derived from XPS analysis by applying Scienta sensitivity factors for the core levels. The position of $\mathrm{E}_{\mathrm{F}}$ with respect to the valence band maximum $(\mathrm{VBM})$, and states in the gap below $\mathrm{E}_{\mathrm{F}}$, were determined from analysis of the valence band spectra. A bulk rutile sample from Goodfellow was used as a reference bulk material for the $\mathrm{TiO}_{2}$ films. No special surface treatment such as ion etching in the analysis apparatus was carried out for rutile or the films. An electron flood gun was used to compensate the accumulation of surface electrostatic charge onto the samples during analysis. Two runs of measurement were made on each film and five on rutile.

\section{c- UV-Visible optical spectrophotometry}

Optical reflectance measurements were made on films deposited on glass substrates, with a Jasco V-550 spectrophotometer in the 300-900 nm wavelength range. Calibration has been realized with sapphire, a material whose refractive index is the order of the sample's one, in order to assess the experimental measurement error, which was found as $0.5 \%$. Care was taken to absorb any possible reflected beam from the rear face of sapphire or substrates by a black carbon strip in order to avoid any back-reflected wave. Reflectance spectra $R_{\exp }$ were recorded in the visible range, at normal incidence.

\section{$d-X R D$}

The phase structure of the films was determined by using a Seeman-Bohlin (grazing angle configuration) $\mathrm{X}$-ray diffractometer with $\mathrm{Cu} \mathrm{K} \alpha$ radiation at an incident angle of $3^{\circ}$, in steps of $0.02^{\circ}$.

\section{III- Results and discussion}

\section{III.1- Film composition and density from RBS analysis and correlation with deposition rate:}

All films can be described as $\mathrm{TiO}_{2-\mathrm{x}}$ and their composition was obtained by RBS. Table 1 reports the $\mathrm{O} / \mathrm{Ti}$ atomic ratio given by $\mathrm{RBS}$. The films with the higher $\mathrm{O} / \mathrm{Ti}$ value are those grown in pure argon plasma, the $\mathrm{O} / \mathrm{Ti}$ reaches a flat regime when oxygen concentration in the gas is higher than $10 \%$.

The measured film thickness and the number of atoms per $\mathrm{cm}^{2}$ unit surface allow the calculation of the atomic density of films. For the $F_{10}(1)$ and $F_{20}(1)$ films however, the relative errors of thickness measurement, $13 \%$ and $20 \%$ respectively, were too high, then we have used the thickness given by the simulations of the optical reflectance and given in Table 1 . 
Fig. 1 shows the atomic density of films: clearly, films $F_{0}(1)$ and $F_{0}(2)$ grown in pure argon plasma have the higher density. The decrease in density when adding $\mathrm{O}_{2}$ to $\mathrm{Ar}$ in the feed gas appears more evident for films grown with a $-550 \mathrm{~V}$ cathode self-bias voltage (group $\mathrm{F}_{\mathrm{i}}(1)$, $\mathrm{i}=3,10,20$ in Table 1). The lowest value was found for film $\mathrm{F}_{20}(1)$, a value $\sim 30 \%$ lower than the nominal value of rutile.

The variation of the film density with both the cathode voltage and the oxygen concentration in the gas can be understood by also considering the variation of the film deposition rate. This parameter is plotted in Fig.1(b). As expected, the higher the voltage, the higher the rate. As can also be seen, $\mathrm{O}_{2}$ introduction resulted in a less efficient sputtering process owing to the fact that the partial pressure of Ar was lowered upon $\mathrm{O}_{2}$ addition in the gas, which decreased $\mathrm{Ar}^{+}$ion density in the plasma too.

Globally, the voltage conditions at the cathode which led to higher deposition rates led also to higher film density. However, as said above, within a film series deposited at a same cathode voltage, film density varied strongly with $\mathrm{O}_{2}$ concentration in the gas mixture. This result is to be more likely correlated with the energetic conditions at the substrate. The density decrease obtained when $\mathrm{O}_{2}$ was added can reasonably be explained by a more open structure due to less efficient interaction between the growing film and the most energetic species of the plasma. Plasma-surface interaction through ion bombardment is known to increase surface mobility of the impinging atoms on the substrate or on the growing film surface, leading to film densification.

\section{III.2- Chemical states and film surface stoichiometry from XPS analysis}

The XPS analyses regarded all of core levels Ti2p, O1s and valence band spectral regions. Carbon core level spectrum was also acquired. Carbon stems from surface hydrocarbon contaminants, it also serves as a reference to correct the binding energy (BE) shift due to surface electrostatic charging, either under flood electron gun application or without. The $\mathrm{C} 1 \mathrm{~s}$ spectrum has been set at $285 \mathrm{eV}$, the same shift has been applied to scale all BE spectra discussed below.

Fig.2 (a) displays the Ti2p core level spectrum related to bulk rutile. It consists of Ti2 $\mathrm{p}_{3 / 2}$ and Ti2 $\mathrm{p}_{1 / 2}$ contributions located at $458,35 \mathrm{eV}$ and $464,02 \mathrm{eV}$ respectively. The peaks are wellfitted with symmetric gaussian-lorentzians. The Ti2p3/2 BE agrees well with published data for $\mathrm{Ti}^{4+}$ states in $\mathrm{TiO}_{2}$ (458,7 eV in [9] and references therein for example). 
The corresponding O1s displayed in Fig.3 (a) is dominated by a peak at $529,75 \mathrm{eV}$, i.e. 71.40 $\mathrm{eV}$ higher than that of Ti2p3/2. This corresponds well to oxygen $\mathrm{O} 1 \mathrm{~s}$ BE in titanium oxide $[15,16]$. This spectrum can be fitted with four peaks: the major one $\mathrm{O}_{\mathrm{I}}$ pertaining to $\mathrm{O}^{2-}$ ions in titanium oxide and the others at 531,01 eV (O $\left.\mathrm{O}_{\text {II }}\right), 532,01 \mathrm{eV}\left(\mathrm{O}_{\text {III }}\right)$ and 533,06 eV (O $\left.\mathrm{O}_{\text {IV }}\right)$. The atomic ratio $\mathrm{O}_{\mathrm{I}} / \mathrm{Ti}$, deduced from $\mathrm{Ti} 2 \mathrm{p} 3 / 2$ and $\mathrm{O}_{\mathrm{I}}$ peak areas, is equal to $1,90( \pm 0,03)$.

The missing oxygen with respect to the ideal formula of the oxide $\mathrm{TiO}_{2}$, could be at the origin of the $\mathrm{O}_{\text {II }}$ contribution. In fact, in many transition metals hydroxylation gives rise to a peak whose energy is close to the $\mathrm{O}_{\text {II }}$ peak one $[17,18]$, due to metal-OH bond formation. However, $\mathrm{O}$ atoms giving rise to $\mathrm{O}_{\text {II }}$ peak are in a ratio with $\mathrm{Ti}$ atoms $\left(\mathrm{O}_{\mathrm{II}} / \mathrm{Ti}\right)$ of $0,62( \pm 0,01)$ : this is much higher than the oxygen deficiency $x=0,1$ in the present stoichiometry $\left(\mathrm{TiO}_{1,9}\right)$ with respect to ideal $\mathrm{TiO}_{2}$. The $\mathrm{O}_{\text {II }}$ peak more likely stems also from oxygen bonded to carbon like in $\mathrm{C}-\mathrm{OH}[19]$, masking any Ti-OH contribution to the present O1s spectrum.

As for the remaining peaks resulting from the spectrum fitting, peak $\mathrm{O}_{\mathrm{III}}$ and $\mathrm{O}_{\mathrm{IV}}$, they have been reported to pertain to either adsorbed molecular $\mathrm{H}_{2} \mathrm{O}[20,21]$ or C-O bondings like O-C$\mathrm{O}$ or $\mathrm{O}=\mathrm{C}-\mathrm{O}[19]$.

Fig.2 (b and c) shows the Ti2p core level spectra related to films $F_{0}(1)$ and $F_{10}(1)$. With respect to that of rutile, Ti2 $\mathrm{p}_{3 / 2} \mathrm{BE}$ are slightly up-shifted respectively to 458,83 and 458,80 $\mathrm{eV}$. This shift is also observed in the O1s spectra (Fig. 3 (b and c)). Actually, such a shift towards higher energies were observed for all films. However, the difference between Ti2p3/2 and $\mathrm{O}_{\mathrm{I}}$ peak BEs remains constant as 71,43 $\pm 0.02 \mathrm{eV}$ and equal to that of rutile: this indicates that the chemical states of $\mathrm{Ti}$ and $\mathrm{O}$ are the same in these films and in rutile. The BE shift observed in the spectra is only related to a variation of $\mathrm{E}_{\mathrm{F}}$ with respect to the core lines, due to band bending caused by a non-zero surface potential during the analysis. Indeed, dealing with semi-conductors materials, band bending is expected in presence of a non-zero surface potential. We verified this effect in the case of rutile. Various spectra were measured under different electron beam energy conditions used for surface charge compensation, which create different sample surface potentials. The latter are reflected in different binding energy shift corrections for misaligned sample and spectrometer Fermi levels. After correction for surface charging, Ti2p and O1s binding energy are given in Table 2; they depend clearly on the energy of the incident electron beam under which the spectra were measured.

The $\mathrm{O}_{\mathrm{I}} / \mathrm{Ti}$ atomic ratios deduced from Ti2p3/2 and $\mathrm{O}_{\mathrm{I}}$ peak areas obtained for all films are displayed in Table 1. Contrarily to O/Ti values from RBS analysis, no clear trend is observed in the variation of the $\mathrm{O}_{\mathrm{I}} / \mathrm{Ti}$ ratio values with the oxygen concentration in the sputtering gas. 
As can be seen, all films are under-stoichiometric. As the XPS-derived $\mathrm{O}_{\mathrm{I}} / \mathrm{Ti}$ atomic ratio regards oxygen in Ti-O-Ti bonds only, the observed deviation " $x$ " in these $\mathrm{TiO}_{2-x}$ films from the ideal stoichiometry $\mathrm{TiO}_{2}$ can be due to structural defects as $\mathrm{O}$ vacancies, either unhealed or healed by $\mathrm{H}_{2} \mathrm{O}$ adsorption giving Ti-OH bonds [22]. Similarly to rutile, the latter cannot be quantified as they are masked by $\mathrm{C}-\mathrm{O}$ bonds in the $\mathrm{O}_{\text {II }}$ peak in $\mathrm{O} 1 \mathrm{~s}$ spectrum. In fact, the $\mathrm{O}_{\mathrm{II}} / \mathrm{Ti}$ atomic ratio is, again as for rutile, in all cases much higher than " $\mathrm{x}$ " in these $\mathrm{TiO}_{2-\mathrm{x}}$ films (Table I).

\section{III.3- Valence band maximum energy}

In rutile, Ti atoms are surrounded by six oxygen atoms, forming a distorted octahedron. Due to crystal field, the Ti3d orbitals split into two sets of orbitals, e grouping $d z^{2}$ and $d x^{2}-y^{2}$ and $t_{2 g}$, grouping $d_{x y}, d_{x z}$ and $d_{y z}$. Oxygen atoms are surrounded by three Ti atoms in a planar geometry. $\mathrm{sp}^{2}$ hybridisation of $\mathrm{O}$ atoms forms three $\sigma$ bonds (from $\mathrm{p}_{\mathrm{x}}, \mathrm{p}_{\mathrm{y}}$ and $\mathrm{s}$ orbitals) in the plane and one $\pi$ bond (from $p_{z}$ ) perpendicularly to the plane. The valence band (VB) spectrum reflects the density of filled states, weighted by the photoemission cross-section. The top of $\mathrm{VB}$ of $\mathrm{TiO}_{2}$ is occupied by $\mathrm{O} 2 \mathrm{p}$ non-bonding states. The e $\mathrm{g}$ states of $\mathrm{Ti} 3 \mathrm{~d}$ orbitals are bonded in $\sigma$ orbitals and are located in the lower energy region of the VB, while the $\mathrm{t}_{2 \mathrm{~g}}$ states are bonded in $\pi$ orbitals and lye higher in energy than the $\sigma$ states, midway between the $\sigma$ states and the O2p non-bonding states [23]. A VB spectrum is displayed in Fig. 4(a) for $\mathrm{F}_{20}(1)$, where the different spectral regions are indicated. For comparison, a fit of the VB spectrum of rutile is also shown in Fig. 4(b). Differences between the two spectra can be observed, in particular in the lowest and in the highest energy sides of the spectra. The assignment of such peaks is given in the following sections.

The valence band maximum energy (VBM) is determined as the zero intensity energy of the low BE region of the spectrum. After a Shirley background subtraction, the VBM energy is found by extrapolating a linear fit of the final spectrum portion to zero-intensity (inset in Fig. 4(a). The obtained values are reported in Table 2, for the films and the rutile reference. For the latter, only a mean value is given.

\section{III.4- Chemical states above the VBM}

The valence band, as described above, did not sign the upper end of the XP spectrum below Fermi level for all the samples. Between VBM and the Fermi level, a low intensity peak can 
be measured, as can be seen in Fig. 4(a) and in the inset therein; its position is given in Table 2 , together with its area ratio to the $T i 2 \mathrm{p}_{3 / 2}$ peak.

Neither rutile nor film $\mathrm{F}_{0}(1)$ spectrum exhibited such a peak, while for all the other films the ratio of this peak to $\mathrm{Ti}_{2} \mathrm{p}_{3 / 2}$ peak varied between $3 \times 10^{-4}$ to $8 \times 10^{-4}$. This feature has been reported for under-stoichiometric titanium oxide. It has been assigned to Ti3d states and attributed to oxygen vacancies which result in partially filled Ti3d nonbonding states in the gap $[9,24,25,26]$. It has been also shown that other defect states like interstitial Ti can give rise to a similar state between the VBM and Fermi level [14].

The area ratio between this gap state peak and Ti2 $\mathrm{p}_{3 / 2}$ was calculated and it is shown in Fig. $5(\mathrm{a})$ in function of the measured $\mathrm{O}_{\mathrm{I}} / \mathrm{Ti}$ atomic ratio. It appears that the relative quantity of the Ti3d states detected above the VBM doesn't follow the deviation " $\mathrm{x}$ " from ideal stoichiometry of the oxide as obtained by XPS, as it should if these states were due to oxygen vacancies. Here, the closer the $\mathrm{O}_{\mathrm{I}} / \mathrm{Ti}$ ratio value to 2 , the higher the $\mathrm{Ti} 3 \mathrm{~d} / \mathrm{Ti}$. In our assumption that the lacking $\mathrm{O}$ atoms to form stoichiometric $\mathrm{TiO}_{2}$ are either $\mathrm{O}$ vacancies or $\mathrm{O}$ atoms involved in Ti-OH bonds which do not contribute to $\mathrm{O}_{\mathrm{I}}$ peak, $\mathrm{O}$ vacancies cannot explain the evolution of $\mathrm{Ti3d} / \mathrm{Ti}$ in Fig. 5(a) as the higher their number, the more intense should be the Ti3d peak. On the contrary, films with more hydroxylated $\mathrm{Ti}$ (i. e. lower $\mathrm{O}_{\mathrm{I}} / \mathrm{Ti}$ ratio value) as a result of $\mathrm{O}$ vacancy healing, should give a lower Ti3d/Ti ratio. This can account for the dependence between the $\mathrm{O}_{\mathrm{I}} / \mathrm{Ti}$ and Ti3d gap states of Fig. 5(a). It is then likely that in regions of the surface sampled by XPS, $\mathrm{O}$ vacancies are healed in the form of Ti-OH bonds by dissociation of foreign $\mathrm{H}_{2} \mathrm{O}$ molecules from ambient.

A fingerprint of hydroxyl groups bonded to Ti can be found in the VB spectra. Ti-OH bonds give a peak at the bottom of this spectrum, at $\sim 11 \mathrm{eV}$ of $\mathrm{BE}$, corresponding to the $3 \sigma$ orbital of the $\mathrm{OH}$ radical $[27,28]$. This peak, indicated in Fig.4(a-b), was observed for all the film and rutile spectra. In Fig. 5(b) its relative area with respect to the VB spectrum is plotted in function of the $\mathrm{Ti} 3 \mathrm{~d} / \mathrm{Ti}$ area ratio. The dependence of the Ti $3 \mathrm{~d}$ sites on the hydroxyl groups number and the healing effect of the latter on the defects is clear.

In contrast with the above XPS analysis which samples the outermost surface layers, RBS gives information about the film composition in its whole volume. Interestingly, the Ti3d/ $\mathrm{Ti} 2 \mathrm{p}_{3 / 2}$ area ratio determined by XPS correlates well with the oxide stoichiometry given by RBS. Fig. 5 (c) shows clearly that the highest relative Ti3d states concentrations are obtained for the lowest $\mathrm{O} / \mathrm{Ti}$ ratio. On one hand, this result would corroborate the attribution of the Ti3d states origin below Fermi level to $\mathrm{O}$ vacancies and, on the other hand, the relationship 
between $\mathrm{Ti} 3 \mathrm{~d} / \mathrm{Ti}$ and $\mathrm{OH} 3 \sigma / \mathrm{VB}$ area ratios indicates that the hydroxyl bonds are not confined at the topmost surface layers but are distributed also in the film volume.

\section{III.5- Film structure from XRD analysis}

$\mathrm{X}$-ray diffraction analysis for films grown in pure argon plasma showed either a featureless spectrum, indicating an amorphous structure, or a typical peak, though of very weak intensity, of rutile nanoparticles. The spectra obtained with oxygen addition to argon gave both rutile and anatase diffraction patterns, whatever the oxygen concentration in the gas and the cathode voltage. The spectra relative to $F_{0}(1)$ and $F_{20}(1)$ films are displayed in Fig. 6 (a) and (b) respectively, as representative of the case of $\mathrm{Ar}$ and $\mathrm{Ar}-\mathrm{O}_{2}$ plasmas $\left(\mathrm{F}_{0}(2)\right.$ film appeared amorphous in these analyses, spectrum not shown). The rutile structure is signed by the (110) peak and anatase is by the (101) diffraction peak.

III.6 - Optical properties from reflectance measurements: complex refractive index and optical gap

Possible gap states above the Fermi level due to O vacancies are not detected by XPS. Optical measurements performed on the films under study were of great help in determining both the fundamental gap of the films and the existence of extrinsic gaps due to defect states and to defining a band energy scheme of the films.

\section{III.6.1- Film complex refractive index}

A series of five films, $F_{0,10,20}(1)$ and $F_{0,20}(2)$, has been studied. Their reflectance spectra $R_{\text {exp }}(\lambda)$ are shown in Fig. 7(a); for clarity, spectra of films $\mathrm{F}_{0,10,20}$ (1) are up-shifted respectively by $0.28,0.6$ and 0.65 . Here, one intends to simulate the shapes of the various spectra and mainly get the refractive and absorption indices of the films and the energy gap of the material. Transmittance measurements (not reported here) have been performed and have showed that absorption exists to a small extent in our films; reflectance spectra $R_{\text {exp }}$ were used in order to extract a thickness " $d$ " and the indices in which absorption is taken into account. The thickest films $F_{0}(2)$ and $F_{20}(2)$ clearly exhibit interferences; then, even if absorption exists, it should remain small but not negligible if one intends to fit calculated and experimental spectra to extract the film complex index $n(\lambda)=v(\lambda)+i \kappa(\lambda)$ or its complex dielectric function $\varepsilon(\lambda)=\varepsilon_{1}(\lambda)+i \varepsilon_{2}(\lambda)$. 
A classical relation [29] gives the theoretical expression of Fresnel reflectance $R$ of a film deposited onto a substrate: $R_{\text {Fresnel }}=\rho \rho^{*}$ where

$$
\rho=\frac{\rho_{12}+\rho_{23} e^{2 i k d}}{1+\rho_{12} \rho_{23} e^{2 i k d}}
$$

$k$ is the wave vector inside the film, $\rho_{12}$ is the vacuum-film reflection coefficient, $\rho_{23}$ that of the film-substrate interface.

A multi-step calculation procedure was applied in order to determine starting data with a good approximation, which consisted in successively using the following models:

- Sellmeier and Wemple-Didomenico (W) [30] models; the latter expresses $v(\lambda)$ in the transparency domain of the material but recalling absorption explicitly through a measure of the strength of interband optical transitions $\left(\mathrm{E}_{\mathrm{d}}\right)$ and the single oscillator energy associated with the maximum of absorption $\left(\mathrm{E}_{0}\right): v_{W}{ }^{2}=1+\frac{E_{0} E_{d}}{E_{0}{ }^{2}-E^{2}}$

- Forouhi-Bloomer (F-B) model to calculate $\kappa_{F-B}(\lambda)$ [31], which, used with $v_{W}(\lambda)$ previously estimated, served as entry data for reflectance simulation; F-B'model leads to first values of the energy gap $E_{g}: \kappa_{F-B}=\frac{A^{\prime}\left(E-E_{g}\right)^{2}}{E^{2}-B^{\prime} E+C^{\prime}}$

- Ketteler-Helmholtz model $(\mathrm{K}-\mathrm{H})$, based on the complex dielectric function and in which transparency and absorption domains are consistently taken into account. In contrast with what was done in the previous steps, within $\mathrm{K}-\mathrm{H}$ model the real and imaginary part of the dielectric function are determined simultaneously. $d, v_{W}(\lambda)$, $\kappa_{F-B}(\lambda)$ and $E_{g}$ determined above served as input data in order to determine $\nu_{K-H}(\lambda)$ and $\kappa_{K-H}(\lambda)$ which were the final values of these calculations.

The substrate index has been determined first (the calculations are given in Appendix A). Each step of the film reflectance simulation is described in more details in appendix B.

Fits between $R_{\text {exp }}$ and $R_{\text {Fresnel }}$ were performed and, in the following, we give the final results of the calculations. Fig.7(b) shows the agreement that has been obtained by our simulations between $R_{\text {exp }}$ and $R_{\text {Fresnel }}$ for film $\mathrm{F}_{0}(2)$ and $v(\lambda)$ and $\kappa(\lambda)$ are given in Fig. 8 (a) and (b) respectively. What can be noticed is that $v(\lambda)$ varies significantly among the various samples. In order to better illustrate this result, the real part $v(\lambda)$ of $n(\lambda)$ corresponding to $\lambda=632,8$ nm (i.e. the He-Ne laser wavelength commonly used for ellipsometry) is plotted in Fig. 9 in function of the atomic ratios O/Ti from RBS (plot a) and $\mathrm{O}_{\mathrm{I}} / \mathrm{Ti}$ from XPS (plot b). Except for 
$F_{10}(1)$ (not represented), all the points are fairly aligned in Fig.9(a) following a decreasing linear function with $\mathrm{O} / \mathrm{Ti}$ from RBS. By considering the relationship between this ratio and the Ti3d states relative amount (Fig.5(c)) and between the amount of the Ti3d states and $\mathrm{OH}$ states (Fig. 5(b)), the effect of hydroxylation on $v(\lambda)$ value become clear. This is also what can be observed in Fig. 9(b): $v(\lambda)$ increases with $\mathrm{O}_{\mathrm{I}} / \mathrm{Ti}$ from XPS. So, in determining the film refractive index values is the extent to which water interacts with the films. This can be due to the film internal structure itself as a low refractive index is usually related to a low packing density of the film grains or columns. With a high melting point material like titanium oxide $\left(1867^{\circ} \mathrm{C}\right)$, films grown at room temperature as the present ones are more likely of a columnar structure [32]. The surface area of the columns can affect strongly the refractive index values [33]. On the other hand, for these films, crystallisation can also be a factor of the higher values of refractive index of the films grown in presence of oxygen [34, 35]: XRD analysis revealed an amorphous state or weak crystallinity of the films deposited in a pure Ar plasma while a stronger crystallinity (though at nanoscale) was observed in all films grown in Ar- $\mathrm{O}_{2}$ plasma, as shown in Fig. 6. Correspondingly, the $v(632,8 \mathrm{~nm})$ values of $\mathrm{F}_{0}(1)$ and $\mathrm{F}_{0}(2)$ are lower than those of $F_{20}(1)$ and $F_{20}(2)$. The variations of the refractive index of the present films appear to be determined by both crystallinity and packing density which, in turn, determines the hydroxylation extent.

Finally, the imaginary part $\kappa(\lambda)$ of $n(\lambda)$ has been used to determine the optical band gap of the films, this is discussed in the next section.

\section{III.6.2 - Film optical gap from $\kappa_{K-H}(\lambda)$ and gap states:}

The optical band gap can be determined from the absorption coefficient $\alpha=4 \pi \kappa / \lambda$. Tauc model [36] describes $\alpha$ in the high absorbance region of the wavelength range as:

$\alpha \mathrm{E}=\mathrm{A}\left(\mathrm{E}-\mathrm{E}_{\mathrm{g}}\right)^{\gamma}$

where $\mathrm{E}$ is the incident photon energy, Eg is the energy gap, A a constant independent of $\mathrm{E}$ and $\gamma$ has four possible numeric values: $1 / 2,2,3,3 / 2$. Generally an ad hoc assumption is made of a kind of transition (direct allowed when $\gamma=1 / 2$, indirect allowed when $\gamma=2$, indirect forbidden for $\gamma=3$ and direct forbidden for $\gamma=3 / 2)$ and the $(\alpha \mathrm{E})^{1 / \gamma}$ versus $\mathrm{E}$ curve is fitted with a linear function.

$(\alpha E)^{1 / 2}=\mathrm{A}\left(\mathrm{E}-\mathrm{E}_{\mathrm{g}}\right)$ and $(\alpha \mathrm{E})^{2}=\mathrm{A}\left(\mathrm{E}-\mathrm{E}_{\mathrm{g}}\right)$ were plotted versus $\mathrm{E}$ in order to derive a direct and indirect allowed gap, which values are reported in Table 3. As it can be seen, the values for the direct allowed transitions are higher than for bulk $\mathrm{TiO}_{2}$ which direct allowed gap can be of 
3,3 - 3,4 eV [37]. This can be related to amorphicity or to a quantum size effect due to a nano-crystallinity in the film structure.

On the contrary, the $\mathrm{E}_{\mathrm{g}}$ energy values corresponding to an indirect allowed transition resulted lower (between 2,04 and 2,93) than what reported in literature for titanium oxide $(3,02-3,19$ $\mathrm{eV}$ respectively) [37]. This light absorption is unlikely to pertain to the intrinsic band structure of the films, but rather to absorption by intrinsic defects. In order to check the existence of such a transition mode, no a priori assumption was made for the $\gamma$ value in Eq. 2, rather the $\alpha \mathrm{E}$ versus $\mathrm{E}$ curve is fitted following:

$\operatorname{Ln}(\alpha \mathrm{E})=\operatorname{Ln} \mathrm{A}+\gamma \operatorname{Ln}\left(\mathrm{E}-\mathrm{E}_{\mathrm{g}}\right)$

The $E_{g}$ value as well as $\gamma$ value are obtained as curve fit results. In the inset of Fig. 8(b) such a curve fit is shown for film $F_{20}(1)$ for photon energies $\geq 3,5 \mathrm{eV}$. The fit results regarding $\mathrm{E}_{\mathrm{g}}$ and $\gamma$ are summarized in Table 3 for all the films. This method allowed to identify the dominant transition mode in the photon energy range under study. In the case of $F_{10}(1), \gamma=$ 0,66 indicating rather a direct allowed transition and confirming that for $\mathrm{E} \geq 3,5 \mathrm{eV}$, the intrinsic gap is direct. For all other films, we can see that $\gamma$ is close to 2 . No value of $\gamma$ representative of a forbidden direct or indirect transition resulted from the fit following Eq. 3 . So, only the allowed transitions are likely to occur. All the energies fall in the visible range. For $F_{10}(1)$, a second gap value of 2,69 eV could be found by fitting $\operatorname{Ln}(\alpha \mathrm{E})$ following Eq. 3for $\mathrm{E}<3,5 \mathrm{eV}$, far from the fundamental gap energy region.

Light absorption in the visible can, in fact, be due to lattice defects which create energy levels within the gap of titanium oxide: defects in the oxygen sub-lattice related to $\mathrm{O}$ vacancies and those related to $\mathrm{Ti}^{\mathrm{n}+}(\mathrm{n}=3$ or/and 2) ions. Although literature is abundant for the electronic structure of titanium oxide, many recent papers recognize that there still exists insufficient information on the optical properties of point defects. In a review made by Kuznetsov and Serpone [38], the absorption bands in the visible spectral region are reported to be associated to $\mathrm{O}$ vacancies, which act as F-type color centers in a range of 2,93- $2 \mathrm{eV}$. In this case, light absorption can originate from transitions between the defect-induced energy levels inside the gap and the Ti3d levels in the conduction band (CB). Let's recall that there are three types of the F-type centers: doubly-ionized and optically silent $\mathrm{O}$ vacancies (the so-called $\mathrm{F}^{++}$centers), $\mathrm{O}$ vacancy with one trapped electron $\left(\mathrm{F}^{+}\right.$-center) and with two trapped electrons (F-center). In turn, Chen et al. attributed an absorption energy of $1,78 \mathrm{eV}$ for transitions between a $\mathrm{F}^{+}$-center and $\mathrm{CB}$, and one of $0,87 \mathrm{eV}$ for transition involving a $\mathrm{F}$-center and $0,20 \mathrm{eV}$ for a $\mathrm{F}^{++}$-center [39]. 
For our films, the extrinsic absorption energy values found so far fall in the interval 2,60 $2,78 \mathrm{eV}$ as it can be seen in Table 3, corresponding to wavelengths between $446-470 \mathrm{~nm}$. Such a set of values could be $\mathrm{F}$ - and $\mathrm{F}^{+}$- centers related to $\mathrm{O}$ vacancies [40], although no unambiguous identification can be made.

Moreover, at variance with the other films, the film $F_{10}(1)$ shows an increase of $\kappa(\lambda)$ beyond $\sim 850 \mathrm{~nm}$ (below $\sim 1,45 \mathrm{eV}$ ). The trend of $\kappa(\lambda)$ in this region clearly indicates absorption in the near infra-red which could be associated with $\mathrm{Ti}^{3+}$-related centers $\left(\mathrm{Ti}^{3+}\right.$ in substitutional or interstitial sites) [38, 40].

\section{III.7- Electronic band structure scheme:}

In order to define a band structure of the various films of this study, optical results were used in conjunction with XPS analysis of the valence band. In Fig. 10, a schematic representation of the band structure is given, which shows the VBM energy, the conduction band minimum $(\mathrm{CBM})$ and the gap states, all referred to the Ti2 $\mathrm{p}_{3 / 2}$ BE. This reference level of energy was chosen in order to get rid of band bending effects due to surface states.

It can be seen that in the films the band edges move with respect to that of rutile, there is a recession of the VBM, probably due to the disappearance of states at the top of the band in relation with the oxygen deficiency. As for the intermediate states inside the gap, two extreme cases can be assumed concerning their positioning on the energy scale: the transitions occur between the VBM and the color center level (Fig.10(a)) or between the center level and the CBM (Fig. 10(b)). The first case would place the defect related level above the Ti3d states while, in the second one, it would be between the Ti3d states and the VBM. The latter case is unlikely because no significant peak was observed in that region of the films XP spectra. Besides, in Fig. 10(a), the energy difference $\delta$ between the color center level and CBM is reported. The values are close to those of Chen et al [39] for F-color center absorption in rutile, i.e. O vacancies with two trapped electrons.

\section{IV-Summary}

In this study, $\mathrm{TiO}_{2-\mathrm{x}}$ films were deposited by $\mathrm{RF}$ sputtering in $\mathrm{Ar}-\mathrm{O}_{2}$ mixtures at room temperature. Emphasis was put on the structural and optical properties of the films in order to define a method based on a combined use of x-ray photoelectron and optical reflectance spectroscopies. The intrinsic defects were also studied in conjunction with RBS analysis and a scheme of the energy band structure of the films was proposed. 
In order to quantify optical behaviour, the experimental reflectance spectra were fitted within the frame of a multi-step procedure using different models. This approach was necessary to rigorously derive the film optical constants for a spectral region where absorbance cannot be totally neglected in spite of a high transparency.

The following conclusions were drawn from this study:

(1) All the films were oxygen-deficient and adding oxygen to the sputtering gas was found to further increase the deviation from a full stoichiometry.

(2) The reduced oxide state in the films induced states related to O-vacancies between the VBM and the Fermi level which were strongly correlated with hydroxylation.

(3) Hydroxylation did not appear confined to the surface layers but concerns the film volume as well and had an effect on the refractive index.

(3) O-vacancies made band edges recede, due to energy states disappearance from the top of the VB.

(4) Intermediate bands inside the fundamental gap were likely due to the F-centers.

\section{Acknowledgements:}

The financial support of the "Fondazione Caritro" (Trento) in the frame of Oxi-Solar project is gratefully acknowledged.

N.L. thanks Nice Sophia-Antipolis University for the support of her stay at "Laboratoire de Physique de la Matière Condensée”.

Appendix A: Index of the substrate

The rear face of the substrate being blackened, its reflectance is expressed by $R_{s}=\left(\frac{n_{s}-1}{n_{s}+1}\right)^{2}$ and does not show interference fringes. The substrate index $\mathrm{n}_{\mathrm{s}}(\lambda)$ is involved in the relations that express the reflectance of the film deposited onto its substrate and it must be known prior to the interpretation of optical spectra of $\mathrm{TiO}_{2}$ films. $\mathrm{n}_{\mathrm{s}}(\lambda)$ has been developed in series $n_{s}^{2}=a_{0}+\frac{a_{1}}{\lambda}+\frac{a_{2}}{\lambda^{2}}+\frac{a_{3}}{\lambda^{3}}+\frac{a_{4}}{\lambda^{4}}$ and limited to the fourth order in $\lambda$, no gain being added with higher orders. From $R_{s}$, one extracts $n_{s}(\lambda)$. The $a_{i}{ }^{\prime} s$ are determined by a least square procedure which gave $a_{0}=2,248, a_{1}=-16,7 \mathrm{~nm}, a_{2}=41617 \mathrm{~nm}^{2}, a_{3}=-5518400 \mathrm{~nm}^{3}$ and $a_{4}=-43112 \mathrm{~nm}^{4}$. 
Appendix B: Film optical parameters calculations from reflectance spectra

\section{B.1 First step: calculation of $v(\lambda)$}

Absorption is neglected; a Sellmeier model of bulk $\mathrm{TiO}_{2}$ index $n(\lambda)$, valid for $\lambda>430 \mathrm{~nm}$ [41], gives

$n^{2}(\lambda)=a^{\prime}+\frac{b^{\prime} \lambda^{2}}{\lambda^{2}-c^{\prime}}+\frac{d^{\prime} \lambda^{2}}{\lambda^{2}-e^{\prime}}$

This allows to obtain an order of magnitude of $n(\lambda)$ by a simple mean.

In the transparency domain and within Wemple-Didomenico model (W) [30], the real part $v_{W}{ }^{2}$ of $n(\lambda)$ can be transformed as

$v_{W}^{2}(\lambda)=1+\frac{\lambda_{0 W}}{\lambda_{D W}} \frac{\lambda^{2}}{\lambda^{2}-\lambda_{0 W}^{2}}$

The authors give $E_{d}=25,7 \mathrm{eV}$ which corresponds to $\lambda_{D W} \approx 48,11 \mathrm{~nm}$ and $E_{0}=5,24 \mathrm{eV}$ corresponds to $\lambda_{0 W} \approx 236 n m$, then $\frac{\lambda_{0 W}}{\lambda_{D W}}=4,0548$. For $\mathrm{TiO}_{2}$, Eq.5 is valid for $\lambda>\lambda_{\text {gap }}$.

Remark that, for $\lambda=550 \mathrm{~nm}, c^{\prime} \approx 22,44$ and $\frac{d^{\prime} \lambda^{2}}{\lambda^{2}-e^{\prime}} \approx 0,0026$; then Eq.5 is formally equivalent to Eq.4 if one neglects the third term in the latter and let $a^{\prime} \approx 1, \quad b^{\prime} \approx \frac{\lambda_{0 W}}{\lambda_{D W}}$ and $c^{\prime} \approx \lambda^{2}{ }_{0 W}$

The "optical" thickness $d$ has been determined for each film. Actually, Wemple's model describes the properties of the "red part" of $\mathrm{TiO}_{2}$ optical spectrum. An agreement between calculated and experimental spectra that reproduces their general shape while fitting the "red peak" is obtained with the values given in Table 1. These thicknesses will be used whatever the model for absorption.

\section{B.2 Second step: calculation of $\kappa_{F-B}(\lambda)$}

As derived from $\mathrm{W}$ simulations, an absorption band exists at $\lambda_{0 W} \approx 236 \mathrm{~nm}$. Sellmeier and $\mathrm{W}$ models assume that the absorption band would be far enough for its influence to be negligible. In the various simulations of $R_{\text {exp }}$, we found that one could not consider that this was the case. Actually, $\lambda_{0 w}$ is close to the wavelength range under study and is responsible for the difficulties encountered along the index solving procedure. This absorption band has been taken into account with F-B [31] formalism given in Section III.6.1. Once the extinction 
coefficient $\kappa_{F-B}(\lambda)$ is introduced in $\mathrm{n}(\lambda)$, Eq. 5 must be slightly modified, since the numerical values of $v(\lambda)$ that have led to $v_{W}(\lambda)$ were obtained assuming that $\kappa(\lambda)=0$. More generally, Eq. 5 writes

$$
v_{W}^{2} \approx A+\Delta \frac{\lambda^{2}}{\lambda^{2}-\lambda_{0}^{2}}
$$

The magnitude of $A$ remains small compared to that of the second term, and so does its influence in the simulations. Using $\kappa_{F-B}(\lambda)$ expression and Eq. 6, and entry data $A \approx 1$, $\Delta=\frac{\lambda_{0}}{\lambda_{D}} \approx 4,9$, the simulation gives $\kappa_{F-B}(\lambda)$ that realize the best fit between $R_{\text {exp }}$ and $R_{F r e s n e l}$.

In $R_{\text {exp }}$ simulations, $\lambda_{0}$ is found to influence the position of extrema in the blue part of spectra; for our series of samples, the best fit occurs when the mean value $\left\langle\lambda_{0}\right\rangle \approx 231,8 \pm 3,0 \mathrm{~nm}$, very close to $\lambda_{0 W} \approx 236 \mathrm{~nm}$ already published [30].

\section{B.3 Application of the Ketteler-Helmholtz model}

A set of thicknesses, indices and energy gaps has been estimated through the previous simulations. They serve as entry data for Ketteler-Helmholtz model, in which the real and imaginary part of the dielectric function are determined simultaneously, in contrast with what was done in the previous steps.

The absorption band recognized before is unique in the range under study; the real and imaginary parts of the complex dielectric function $\varepsilon(\lambda)$ of $\mathrm{TiO}_{2}$ are recalled in Eq. 7 and 8.

$$
\varepsilon_{1-K-H}=1+\frac{\Delta \lambda^{2}\left(\lambda^{2}-\lambda_{0}{ }^{2}\right)}{\left(\lambda^{2}-\lambda_{0}{ }^{2}\right)^{2}+\left(\lambda \lambda_{0} \Gamma\right)^{2}}=v_{K-H}^{2}(\lambda)-\kappa_{K-H}^{2}(\lambda)
$$

and

$$
\varepsilon_{2-K-H}=\frac{\Delta \lambda^{3} \lambda_{0} \Gamma}{\left(\lambda^{2}-\lambda_{0}{ }^{2}\right)^{2}+\left(\lambda \lambda_{0} \Gamma\right)^{2}}=2 v(\lambda) \kappa(\lambda)
$$

where $\Delta=\left[\frac{\omega_{p}}{2 \pi c}\right]^{2} \lambda_{0}{ }^{2}=\varphi \lambda_{0}{ }^{2}$ and $\Gamma=\left[\frac{1}{2 \pi c \tau}\right] \lambda_{0}=\beta \lambda_{0}$

Approximate values of a few parameters that enter K-H's relations have been determined according to the following arguments.

- We assume that far from the absorption band, i.e. in the red part of spectra, all models should give more or less the same results. When $\Gamma \lambda \lambda_{0}<<\lambda^{2}-\lambda_{0}^{2}$ and simultaneously $\varepsilon_{2}<<$ $\varepsilon_{1}-1, \mathrm{~K}-\mathrm{H}$ reduces to Sellmeier or Wemple's relations. This implies that one can write 
$\varepsilon_{1-K-H} \approx v_{W}{ }^{2}$ and get approximate input values of $\Delta, \lambda_{0}$ and $\Gamma$. A first run uses Eq. 7 and 8 , simulates $R_{\text {exp }}$ and gives an approximation of $\varepsilon_{1-K-H}(\lambda)$ and $\varepsilon_{2-K-H}(\lambda)$. A first value of $\lambda_{0-K-H}$ comes then from $\varepsilon_{1}-1=0$.

- The end of the whole process described above comes from a few remarks:

From the previous run, the numerical ratio $\frac{\varepsilon_{1}-1}{\varepsilon_{2}}$ can be drawn; it gives a rather linear behaviour (not shown) as a function of $\lambda$, that is expressed by $\frac{\varepsilon_{1}-1}{\varepsilon_{2}} \approx \mathrm{u} \lambda+\mathrm{v}$. At this stage, one gets a new value of $\lambda_{0 K-H} \approx-\frac{\mathrm{u}}{\mathrm{V}}$ from a full K-H treatment, although not yet the most accurate one. In the last run of the simulation, we use the theoretical ratio $\frac{\varepsilon_{1}-1}{\varepsilon_{2}}=\beta^{-1} \frac{\lambda^{2}-\lambda^{2}{ }_{0-K-H}}{\lambda \lambda^{2}{ }_{0-K-H}}$ of Eq.7 / Eq.8, and $\beta^{-1}$ is expanded as a polynomial function of $\lambda$. The fit is improved especially in the spectral zone [300-400] $\mathrm{nm}$ where absorption is important.

Fits for all films have led to the absorption band located at a $\lambda_{0}$ with a mean value $\left\langle\lambda_{0 K-H}\right\rangle=$ $(238,2 \pm 3,1) \mathrm{nm}$.

\section{References}

[1] Akira Fujishima, Xintong Zhang, Donald A. Tryk, Surface Science Reports 63 (2008) 515

[2] K. Yamaguti, S. Sato, J. Chem. Soc. Faraday Trans. I 81 (1985) 1237

[3] M. Grätzel, Nature 414 (2001) 338; M. Grätzel, J. Photochem. Photobiol. C 4 (2003) 145.

[4] Chiu, N. Kikuchi, Appl.Surf. Sci. 255 (2009) 9695

[5] L.R. Sheppard, T. Bak, J. Nowotny, M.K. Nowotny, International Journal of Hydrogen Energy 32 (2007) $2660-2663$

[6] Yasushi Sato, Hideo Akizuki, Toshihisa Kamiyama, Yuzo Shigesato, Thin Solid Films 516 (2008) 5758-5762

[7] B.S. Richards, Solar Energy Materials \& Solar Cells 90 (2006) 1189

[8] C. Strümpel, M. McCann, G. Beaucarne, V. Arkhipov, A. Slaoui, V. Švrcček, C. del Caňizo, I. Tobias, Solar Energy Materials \& Solar Cells 91 (2007) 238

[9] U. Diebold, Surface Science Reports 48 (2003)53 
[10] M. Veronica Ganduglia-Pirovano, Alexander Hofmann, Joachim Sauer, Surface Science Reports 62 (2007) 219-270

[11] X. Li, M. W. Finnis, J. He, R. K. Behera, S. R. Phillpot, S. B. Sinnot, E. C. Dickey, Acta Materialia 57 (2009) 5882

[12] J. Nowotny, T. Bak, M. K. Nowotny, L. R. Sheppard, International Journal of Hydrogen Energy 32 (2007) 2630

[13] T. Bak, J. Nowotny, M. Rekas, C. C. Sorrell, J. of Physics and Chemistry of Solids 64 (2003) 1057

[14] S. Wendt, P. T. Sprunger, E. Lira, G. K. H. Madsen, Z. Li, J. Ø. Hansen, J. Matthiesen, A. Blekinge-Rasmussen, E. 15 Lægsgaard, B. Hammer, F. Besenbacher, Science 320 (2008) 1755

[15] J. Jun, J-H. Shin, M. Dhayal, Appl. Surf. Sci. 252 (2006) 3871

[16] J. F. Moulder, W. F. Stickle, P. E. Sobol, K. D. Bomber, "Handbook of X-ray Photoelectron Spectroscopy”, ( J. Chastaing, R. C. King Jr., Eds., Physical Electronics, Inc. Eden Prairie, 1995)

[17] T. L. Barr, J. Phys. Chem. 82 (16) (1978) 1801

[18] H. M. Liao, R. N. S. Sodhi, T. W. Coyle, J. Vac. Sci. Technol. A 11(5) (1993) 2681

[19] G. Beamson and D. Briggs, "High Resolution XPS of Oraganic Polymers, The Scienta ESCA300 Database”, (John Wiley \&Sons, West Sussex, 1992)

[20] D. Costa - P. Marcus - W.P. Yang, Journal Electrochem. Soc., Vol 141, N¹0, 2669

[21] H.P. Marques, A.R. Canario, A.M.C. Moutinho, O.M.N.D. Teodoro, Applied Surface Science 255 (2009) 7389

[22] L.-M. Liu, P. Crawford, P. Hu, Progress In Surface Science 84 (2009) 155

[23] D. W. Fisher, Phys. Rev. B5 (1972) 4219

[24] C. Di Valentin, G. Pacchioni, A. Selloni, Phys. Rev. Lett. 97 (2006) 166803

[25] L. Fleming, C. C. Fulton, G. Lucovsky, J. E. Rowe, M. D. Ulrich, J. Lüning, J. Appl. Phys. 102 (2007) 033707

[26] T. L. Thompson, J. T. Yates, Chem. Rev. 106 (2006) 4428

[27] S. Eriksen, P. D. Naylor and R. G. Egdell, Spectrochimica Acta 43A (1987) 1535

[28] E. V. Stefanovich, T. N. Truong, Chem. Phys. Lett. 299 (1999) 623

[29] Born, E. Wolf, " Principles of Optics", ( $7^{\text {th }}$ ed., Cambridge University Press, Cambridge, MA, 1999)

[30] S.H. Wemple, M. Didomenico, Phys. Rev. B 3, (1971) 1338

[31] A. R. Forouhi and I. Bloomer, Phys. Rev. B 34 (10) (1986) 7018 
[32] Thornton JA, Hoffman DW. Thin Solid Films 5 (1989) 171

[33] M. Harris, M. Bowden and H. A. Macleod, Optics Communications 51 (1) (1984) 29

[34] A. H. Yuwono, B. Liu, J. Xue, J. Wang, H. I. Elim, W. Ji, Y. Lic and T. J. White, J.

Mater. Chem. 14 (2004) 2978

[35] M. M. Hasan, A. S. M. A. Haseeb, R. Saidur, and H. H. Masjuki, International Journal of Chemical and Biological Engineering 1(2) (2008) 92

[36] J. Tauc, R. Grigorovici, A. Vancu, Phys. Status Solidi 15 (1966) 627

[37] N. Daude, C. Gout, C. Jouanin, Phys. Rev. B15 (6) (1977)3229

[38] V. N. Kuznetsov, N. Serpone, J. Phys. Chem. 113 (2009) 15110

[39] J. Chen, L.-B. Lin, F.-Q. Jing, J. Phys. Chem. Solids 62 (2001) 1257

[40] N. Serpone, J. Phys. Chem. B 110(48) (2006) 24287

[41] E.D.Palik (Ed.), "Handbook of Optical Constants of Solids" (Academic Press, New York, 1985) 
Table 1: Plasma conditions (voltage at the cathode and $\mathrm{O}_{2}$ concentration in $\mathrm{Ar}-\mathrm{O}_{2}$ gas), film thicknesses (geometrical and derived from optical calculations), oxide stoichiometry from RBS analysis, $\mathrm{O}_{\mathrm{I}} / \mathrm{Ti}$ and $\mathrm{O}_{\mathrm{II}} / \mathrm{Ti}$ atomic ratios from XPS analysis

\begin{tabular}{lcccc}
\hline Films & $\mathrm{F}_{0}(1)$ & $\mathrm{F}_{3}(1)$ & $\mathrm{F}_{10}(1)$ & $\mathrm{F}_{20}(1)$ \\
\hline Cathode self-bias (V) & -550 & -550 & -550 & -550 \\
{$\left[\mathrm{O}_{2}\right]$ in Ar- $\mathrm{O}_{2}$ gas } & $0 \%$ & $3 \%$ & $10 \%$ & $20 \%$
\end{tabular}

\begin{tabular}{|c|c|c|c|c|}
\hline Films & $\mathrm{F}_{0}(2)$ & $\mathrm{F}_{3}(2)$ & $\mathrm{F}_{10}(2)$ & $\mathrm{F}_{20}(2)$ \\
\hline Cathode self-bias (V) & -750 & -750 & -750 & -750 \\
\hline $\mathrm{O}_{2}$ in Ar- $\mathrm{O}_{2}$ gas & $0 \%$ & $3 \%$ & $10 \%$ & $20 \%$ \\
\hline$\overline{\text { Films }}$ & $\overline{F_{0}(1)}$ & $\overline{F_{3}(1)}$ & $\mathrm{F}_{10}(1)$ & $\mathrm{F}_{20}(1)$ \\
\hline Thickness (nm) & $82( \pm 4)$ & $46( \pm 10)$ & $39( \pm 5)$ & $40( \pm 8)$ \\
\hline Thickness from reflectance (nm) & 58 & - & 64 & 89 \\
\hline Oxide stoichiometry by RBS & TiO1, 95 & - & $\mathrm{TiO} 1,80$ & $\mathrm{TiO} 1,80$ \\
\hline $\begin{array}{l}\mathrm{O}_{\mathrm{I}} / \mathrm{Ti} \text { atomic ratio by XPS } \\
\text { (based on } \mathrm{O}_{\mathrm{I}} / \mathrm{Ti} 2 \mathrm{p}_{3 / 2} \text { peak area ratio) }\end{array}$ & 1,88 & 1,91 & 1,89 & 1,95 \\
\hline $\begin{array}{l}\mathrm{O}_{\text {II }} / \mathrm{Ti} \text { atomic ratio by XPS } \\
\text { (based on } \mathrm{O}_{\text {II }} / \mathrm{Ti} 2 \mathrm{p}_{3 / 2} \text { peak area ratio) }\end{array}$ & 0,23 & 0,34 & 0,28 & 0,22 \\
\hline$\overline{\text { Films }}$ & $\mathrm{F}_{0}(2)$ & $\mathrm{F}_{3}(2)$ & $\mathrm{F}_{10}(2)$ & $\overline{F_{20}(2)}$ \\
\hline Thickness (nm) & $294( \pm 8)$ & $142( \pm 8)$ & $123( \pm 7)$ & $150( \pm 5)$ \\
\hline Thickness from reflectance (nm) & 230,5 & - & - & 140 \\
\hline Composition from RBS & TiO1, 90 & - & TiO1, 85 & TiO1, 85 \\
\hline $\begin{array}{l}\mathrm{O}_{\mathrm{I}} / \mathrm{Ti} \text { atomic ratio by XPS } \\
\text { (based on } \mathrm{O}_{\mathrm{I}} / \mathrm{Ti} 2 \mathrm{p}_{3 / 2} \text { peak area ratio) }\end{array}$ & 1,90 & 1,93 & 1,89 & 1,93 \\
\hline $\begin{array}{l}\mathrm{O}_{\mathrm{II}} / \mathrm{Ti} \text { atomic ratio } \\
\text { (based on } \mathrm{O}_{\mathrm{II}} / \mathrm{Ti} 2 \mathrm{p}_{3 / 2} \text { peak area ratio) }\end{array}$ & 0,19 & 0,39 & 0,27 & 0,25 \\
\hline
\end{tabular}


Table 2: Corrected binding energy (BE) of Ti2 $\mathrm{p}_{3 / 2}$ and $\mathrm{O} 1 \mathrm{~s}$ peaks for rutile in function of the analysis conditions (flood gun energy) and for the films; corrected Ti3d peak BE and $\mathrm{Ti} 3 \mathrm{~d} / \mathrm{Ti} 2 \mathrm{p}_{3 / 2}$ peak area ratio

\begin{tabular}{|c|c|c|c|c|c|c|c|}
\hline & $\begin{array}{c}\text { Electron } \\
\text { gun energy } \\
(\mathrm{eV})\end{array}$ & $\begin{array}{c}\text { BE shift } \\
\text { correction } \\
(\mathrm{eV})\end{array}$ & $\begin{array}{c}\text { Ti2 } \mathrm{p}_{3 / 2} \\
\mathrm{BE}(\mathrm{eV})\end{array}$ & $\begin{array}{l}\mathrm{O} 1 \mathrm{~s} \\
\mathrm{BE} \\
(\mathrm{eV})\end{array}$ & $\begin{array}{l}\text { VBM } \\
(\mathrm{eV})\end{array}$ & $\begin{array}{l}\text { Ti3d peak } \\
\text { BE }(e V)\end{array}$ & $\begin{array}{c}\mathrm{Ti} 3 \mathrm{~d} / \mathrm{Ti} 2 \mathrm{p}_{3 / 2} \\
\text { area ratio }\end{array}$ \\
\hline \multirow{5}{*}{ Rutile } & 0,5 & $-3,4$ & 458,35 & 529,75 & & Not & 0 \\
\hline & 2 & $-3,03$ & 458,04 & 529,47 & & detected & \\
\hline & 3 & 0,37 & 458,32 & 529,67 & 1,69 & & \\
\hline & 3,5 & 1,23 & 457,86 & 529,26 & $\pm 0,19$ & & \\
\hline & 5 & 4,53 & 458,60 & 529,9 & & & \\
\hline $\mathrm{F}_{0}(1)$ & 5 & 0,75 & 458,83 & 530,27 & 2,81 & $\begin{array}{c}\text { Not } \\
\text { detected }\end{array}$ & 0 \\
\hline $\mathrm{F}_{3}(1)$ & 0 & $-1,18$ & 458,86 & 530,26 & 2,79 & 0,94 & $5,89 \mathrm{E}-4$ \\
\hline $\mathrm{F}_{10}(1)$ & 5 & 0,67 & 458,80 & 530,25 & 2,86 & 1,15 & $3,046 \mathrm{E}-4$ \\
\hline $\mathrm{F}_{20}(1)$ & 5 & 0,7 & 458,85 & 530,33 & 2,95 & 1,09 & $8,13 \mathrm{E}-4$ \\
\hline $\mathrm{F}_{0}(2)$ & 5 & 0,32 & 458,85 & 530,36 & 2,91 & 1,15 & $4,23 \mathrm{E}-4$ \\
\hline $\mathrm{F}_{3}(2)$ & 0 & $-1,1$ & 458,72 & 530,07 & 2,29 & 1,29 & $8,94 \mathrm{E}-4$ \\
\hline $\mathrm{F}_{10}(2)$ & 5 & 0,8 & 458,96 & 530,2 & 2,56 & 1,29 & $4,26 \mathrm{E}-4$ \\
\hline $\mathrm{F}_{20}(2)$ & 5 & 4,85 & 458,78 & 529,99 & 2,60 & 1,22 & $7,08 \mathrm{E}-4$ \\
\hline
\end{tabular}


Table 3 : Optical absorption energies and dominant transition mode

\begin{tabular}{|c|c|c|c|c|c|}
\hline Films & $\begin{array}{c}\text { Indirect } \\
\text { allowed gap } \\
(\mathrm{eV})\end{array}$ & $\begin{array}{c}\text { Direct } \\
\text { allowed gap } \\
(\mathrm{eV})\end{array}$ & $\begin{array}{c}\gamma \text { from } \\
\operatorname{Ln}(\alpha \mathrm{E})=\operatorname{Ln} \mathrm{A}+ \\
\gamma \operatorname{Ln}(\mathrm{E}-\mathrm{Eg})\end{array}$ & $\begin{array}{c}\text { Gap from } \\
\operatorname{Ln}(\alpha \mathrm{E})=\operatorname{Ln} \mathrm{A}+ \\
\gamma \operatorname{Ln}(\mathrm{E}-\mathrm{Eg})\end{array}$ & $\begin{array}{c}\text { Dominant } \\
\text { transition mode }\end{array}$ \\
\hline $\mathrm{F}_{0}(1)$ & 2,6 & 3,61 & 2,01 & 2,76 & Indirect allowed \\
\hline $\mathrm{F}_{10}(1)$ & 2,04 & 3,47 & $\begin{array}{c}0,66 \\
0,53^{*}\end{array}$ & $\begin{array}{c}3,16 \\
2,69 *\end{array}$ & Direct allowed \\
\hline $\mathrm{F}_{20}(1)$ & 2,93 & 3,68 & 2,02 & 2,68 & Indirect allowed \\
\hline $\mathrm{F}_{0}(2)$ & 2,78 & 3,61 & 2,00 & 3,08 & Indirect allowed \\
\hline $\mathrm{F}_{20}(2)$ & 2,64 & 3,65 & 1,94 & 2,51 & Indirect allowed \\
\hline
\end{tabular}

$*$ in $\lambda$ range $<3,5 \mathrm{eV}$ 


\section{Figure captions}

Figure 1: (a) Film atomic density from RBS analysis and (b) deposition rate, in function of $\mathrm{O}_{2}$ concentration in the gas, for cathode voltage $-550 \mathrm{~V}$ and $-750 \mathrm{~V}$.

Figure 2: XPS Ti2p spectra for (a) rutile and ( b) films $F_{0}(1)$ and (c) $F_{10}(1)$

Figure 3: XPS O1s spectra for (a) rutile and( b) films $F_{0}(1)$ and (c) $F_{10}(1)$

Figure 4: Typical XPS VB spectrum and fitting results for (a) $F_{20}(2)$ and (b) rutile

Figure 5: (a) Ti3d/Ti2p area ratio versus oxide stoichiometry from XPS analysis ( $\mathrm{O}_{\mathrm{I}} / \mathrm{Ti}$ ratio)

(b) $\mathrm{OH} 3 \sigma / \mathrm{VB}$ area ratio versus Ti3d/Ti area ratio

(c) $\mathrm{Ti} 3 \mathrm{~d} / \mathrm{Ti} 2 \mathrm{p}$ area ratio versus oxide stoichiometry from RBS analysis $(\mathrm{O} / \mathrm{Ti})$

Figure 6: XRD patterns of $F_{0}(1)$ and $F_{20}(1)$ films

Figure 7: (a) Reflectance $R_{\text {exp }}$ of $\mathrm{TiO}_{2}$ films deposited onto glass substrate (the corresponding thicknesses, as measured by profilometry, are indicated)

(b) Fit between $R_{\text {exp }}$ and $R_{\text {Fresnel }}$ for sample $\mathrm{F}_{0}(2)$

Figure 8: (a) real part of the complex refractive index $v_{K-H}(\lambda)$ for the $\mathrm{TiO}_{2}$ films

(b) imaginary part of the complex refractive index $\kappa_{K-H}(\lambda)$ for the $\mathrm{TiO}_{2}$ films. Inset: Tauc model fit of $\operatorname{Ln}(\alpha \mathrm{E})$ curve for $\mathrm{F}_{20}(1) . \alpha$ is in $\mathrm{cm}^{-1}$

Figure 9: (a) real part of the complex refractive index, $v_{K-H}(\lambda)$, versus RBS O/Ti ratio

(b) imaginary part of the complex refractive index , $\kappa_{K-H}(\lambda)$ versus XPS $\mathrm{O}_{\mathrm{I}} / \mathrm{Ti}$ ratio. The values corresponds to $\lambda=632.8 \mathrm{~nm}$

Figure 10: Band energy scheme for rutile and the $\mathrm{TiO}_{2-\mathrm{x}}$ films with transitions from $\mathrm{VB}$ to the F-type color center level (a) and from the F-type center to CB (b). 
Figure 1

Figure 2




Figure 3




Figure 4

Figure 5
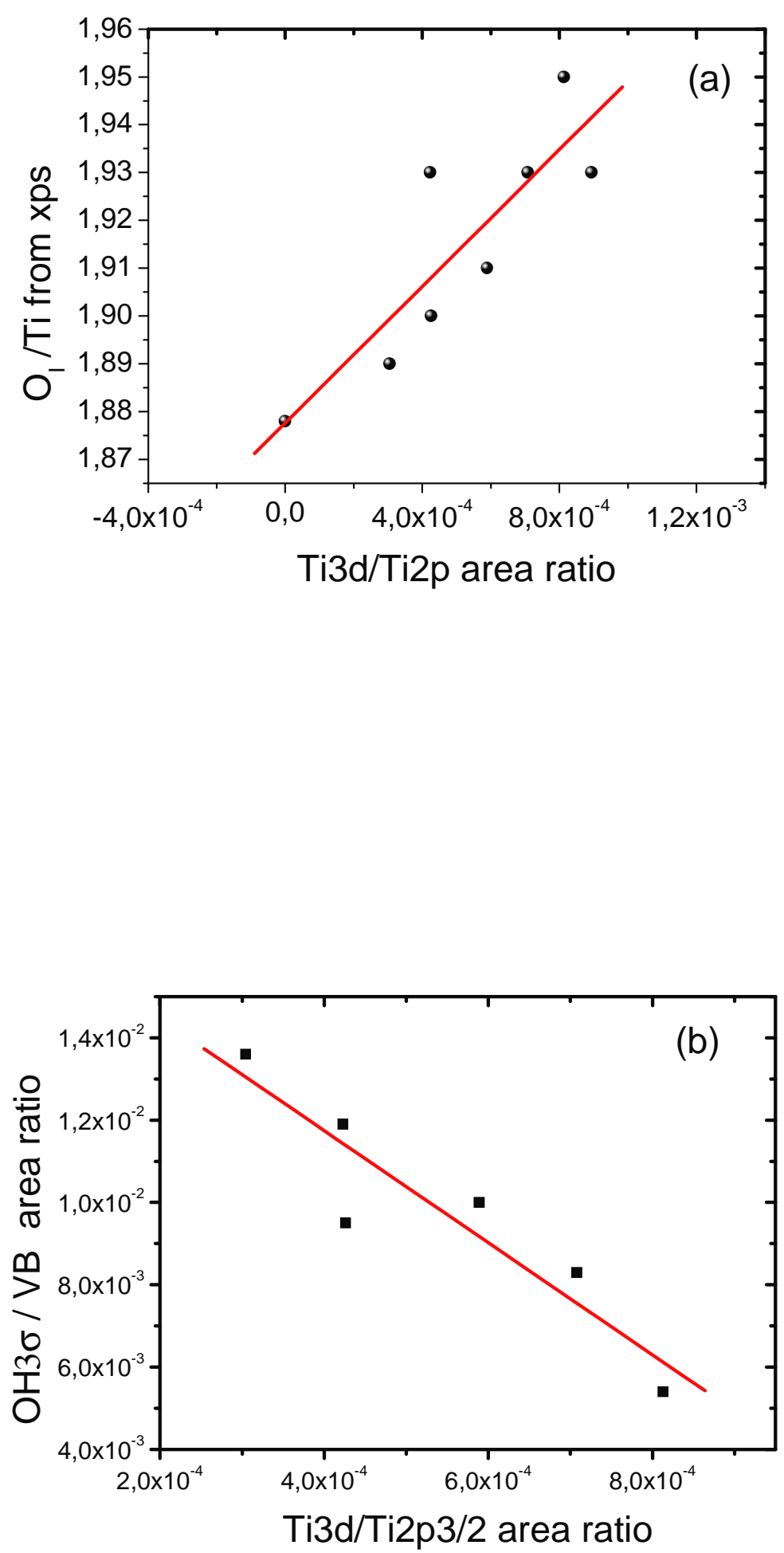


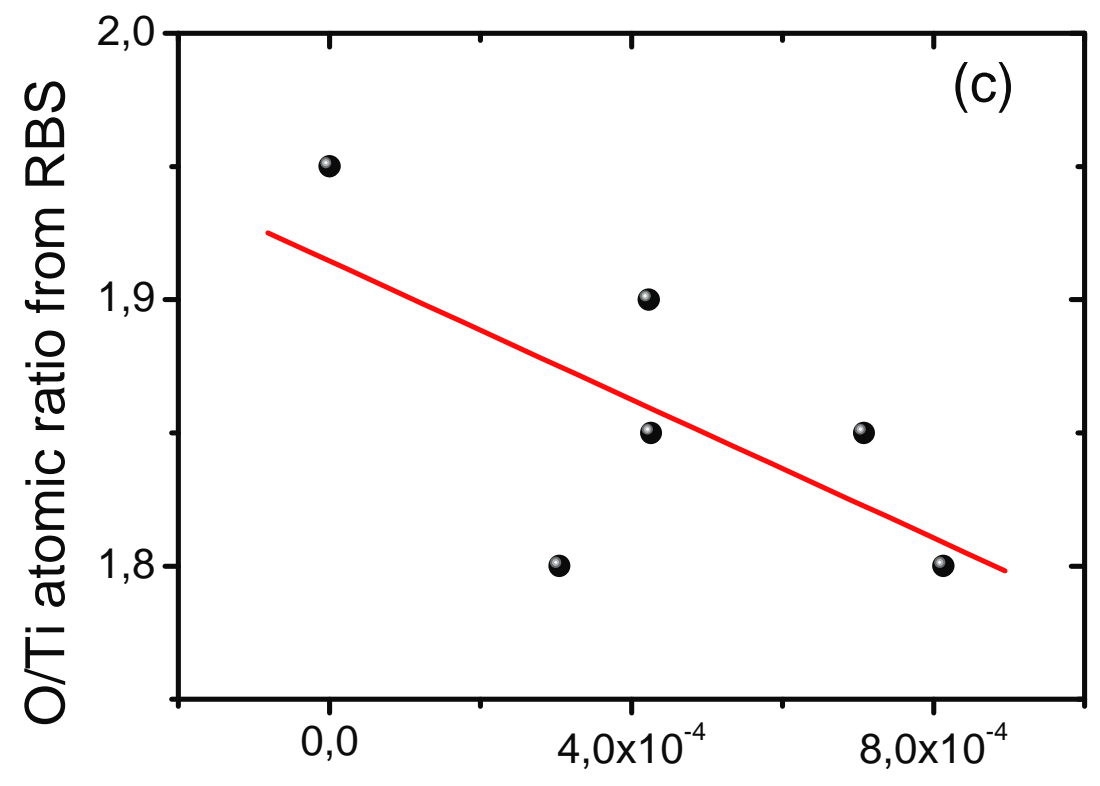

$\mathrm{Ti} 3 \mathrm{~d} / \mathrm{Ti} 2 \mathrm{p}$ area ratio 
Figure 6

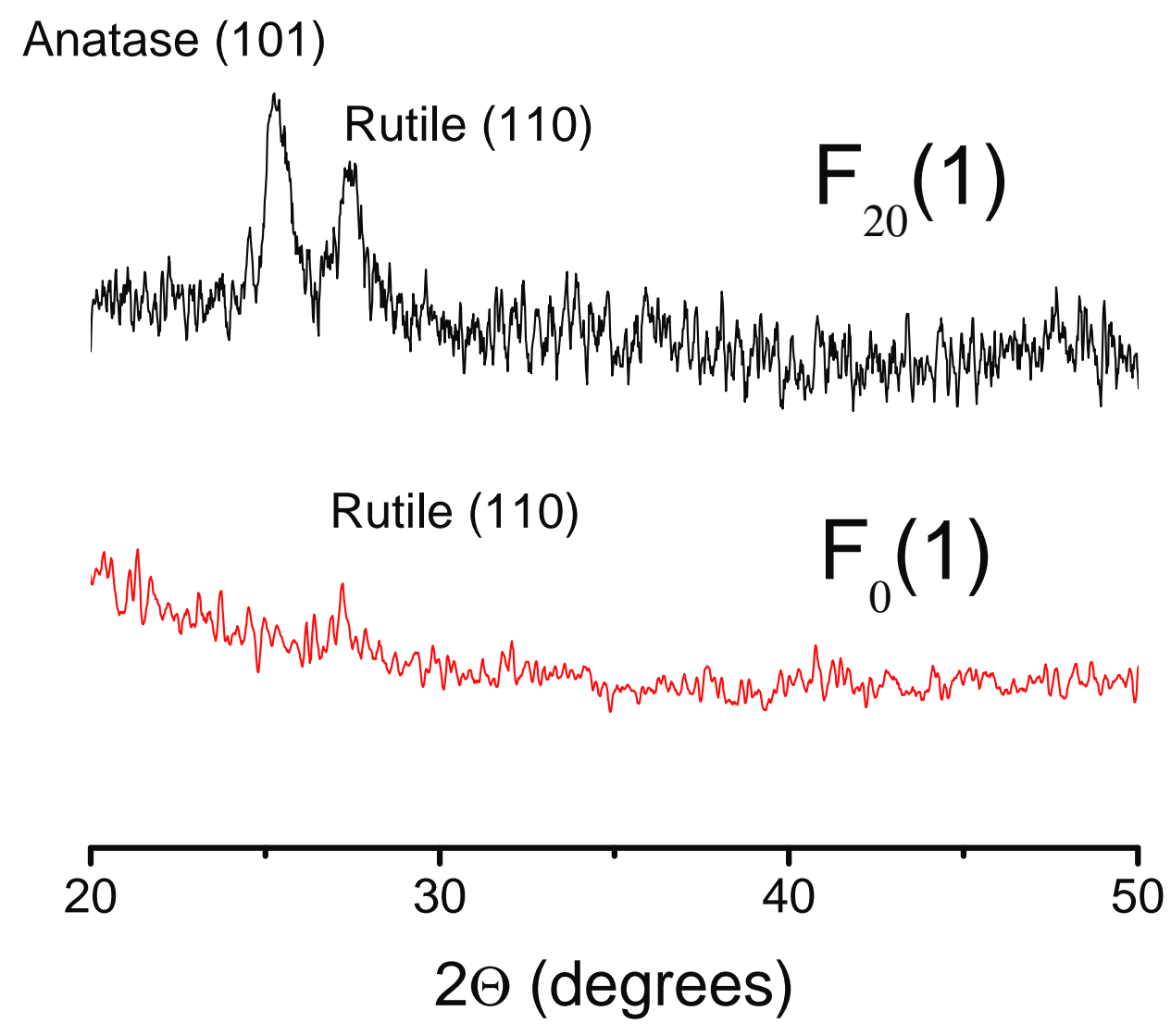


Figure 7
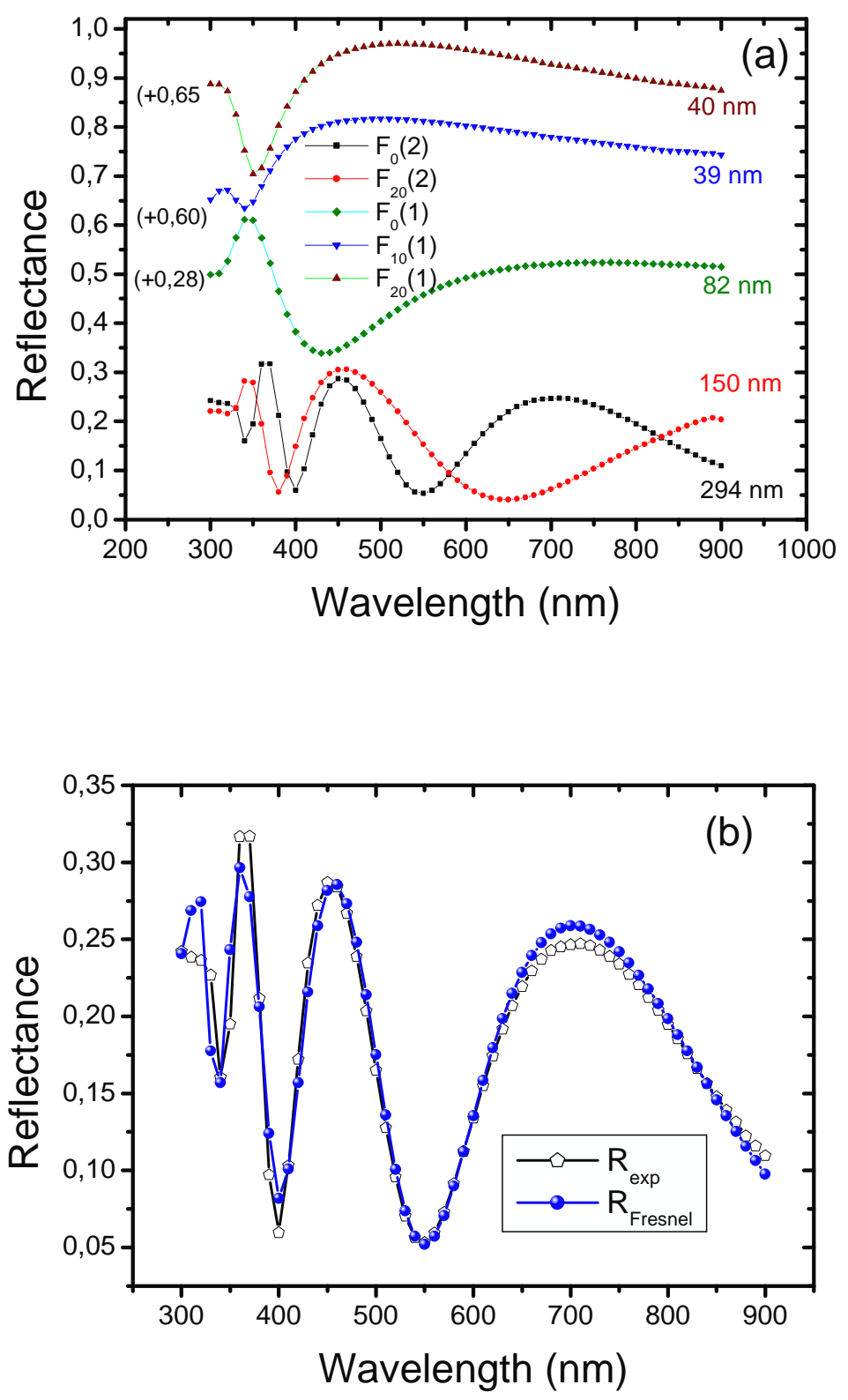
Figure 8
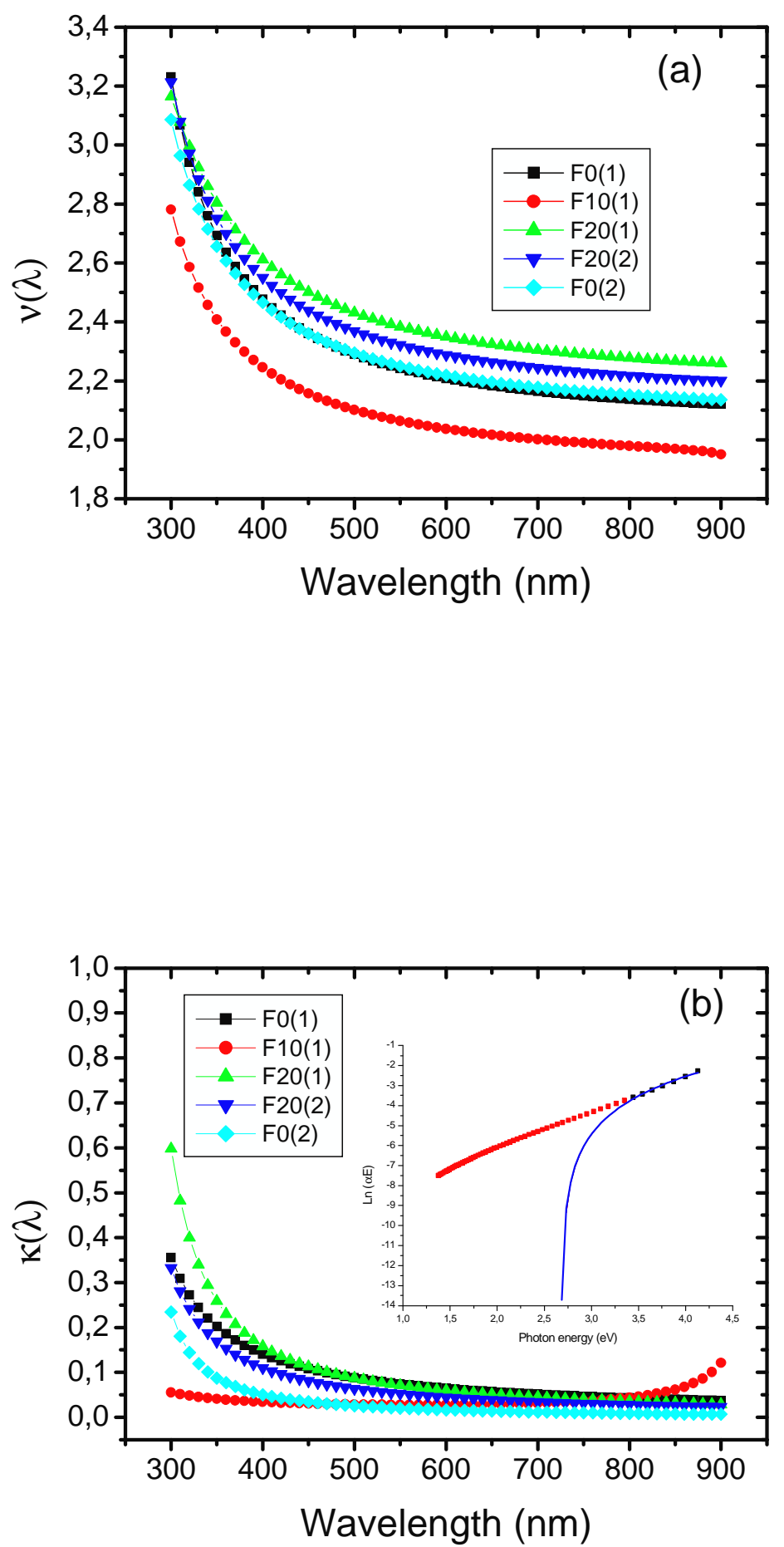
Figure 9
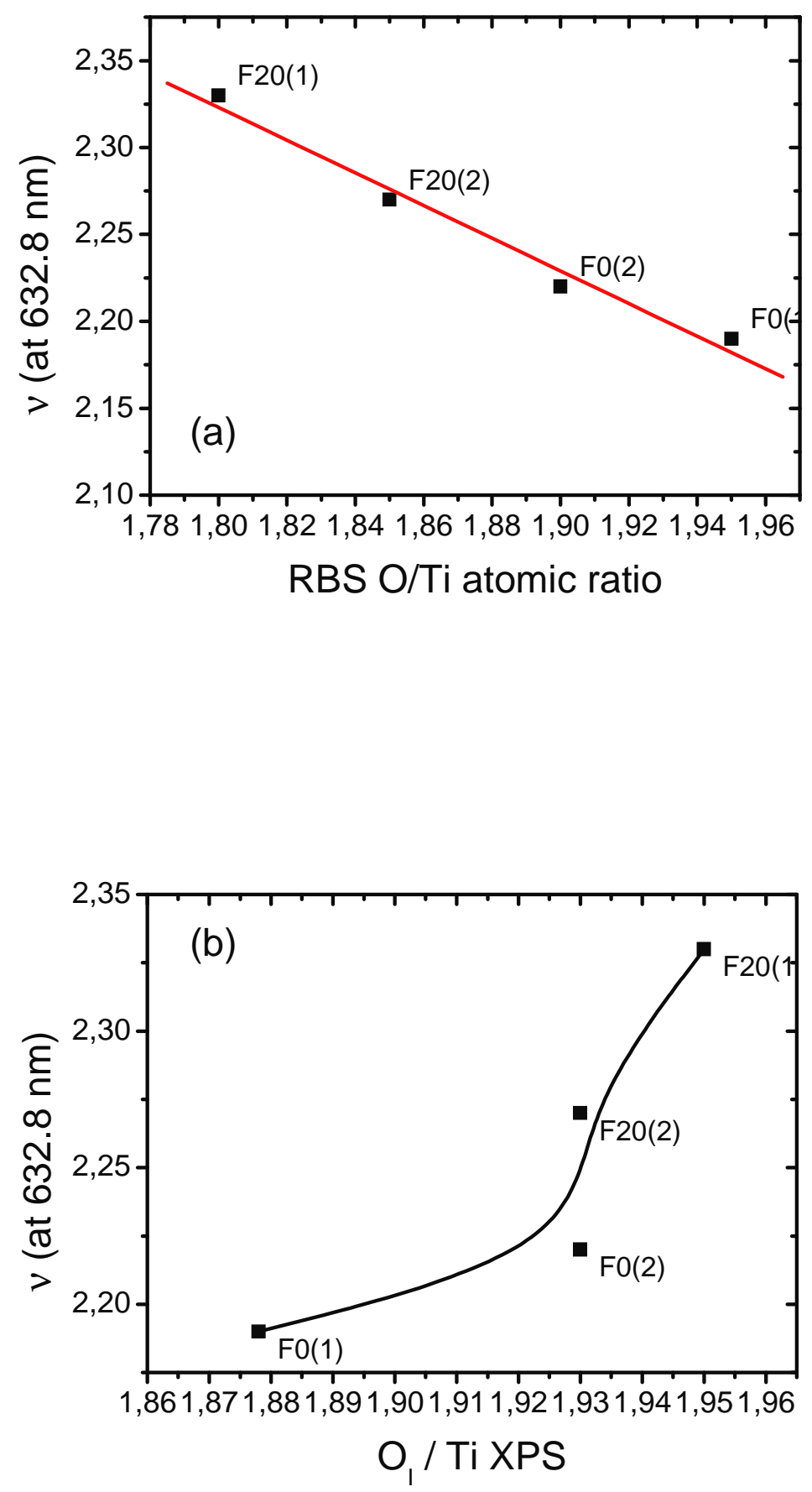
Figure 10

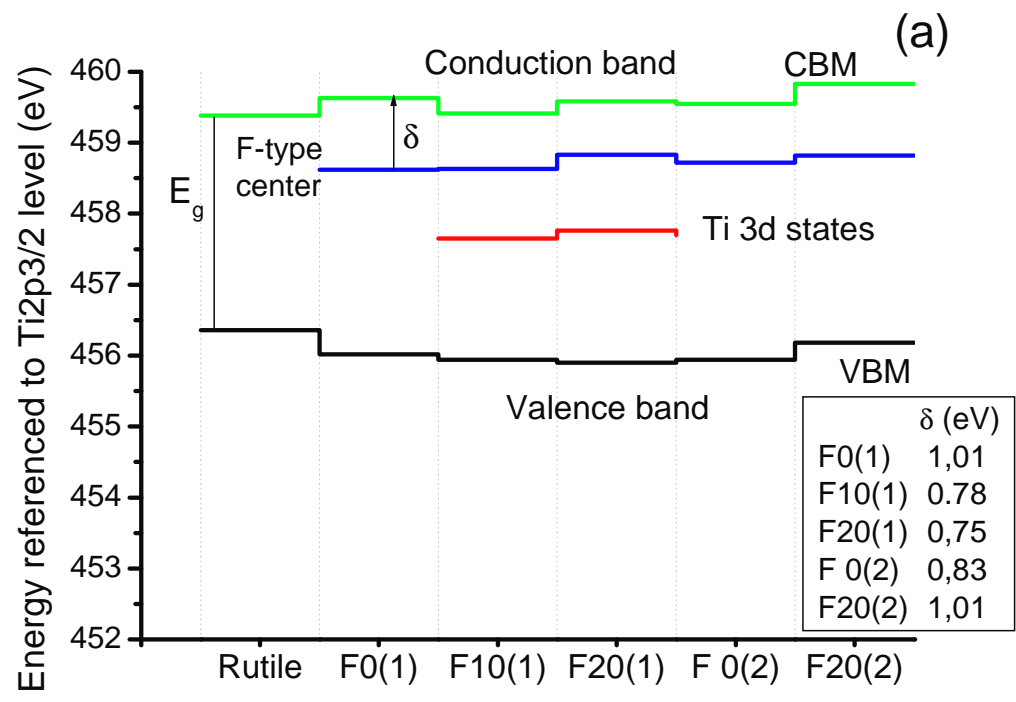

Films

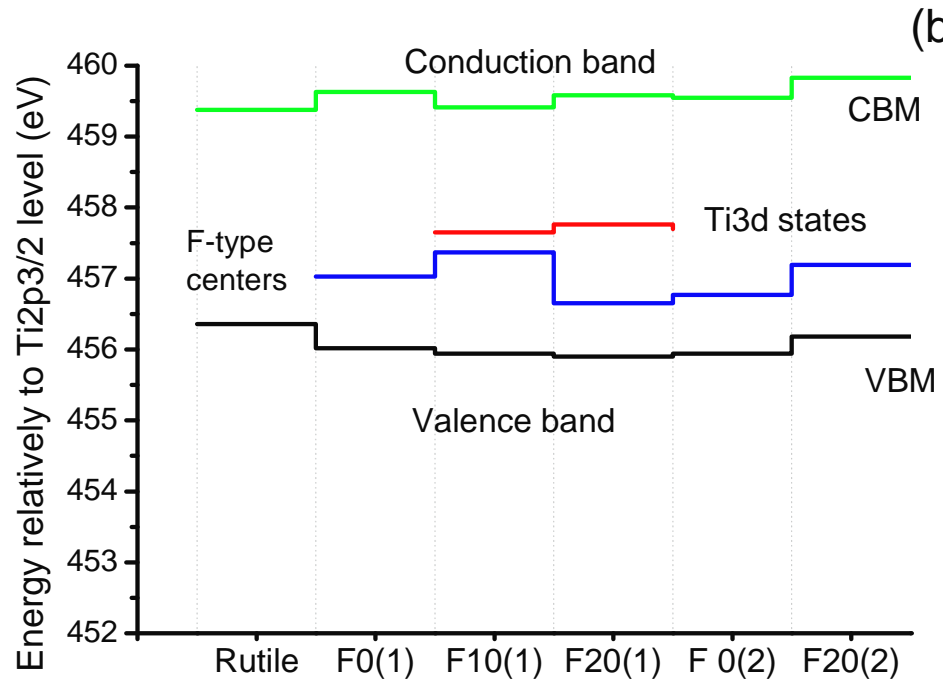

Films 